\title{
Faktor-Faktor yang Berhubungan dengan Pemberian ASI Eksklusif di Wilayah Kerja Puskesmas Rambah Hilir I Kabupaten Rokan Hulu Tahun 2012
}

\author{
Factors Associated With Practice of Exclusive Breastfeeding in The Area of \\ Rambah Hilir I Public Health Center, Rokan Hulu District 2012
}

Herlina Susmaneli

Program Studi Ilmu Kesehatan Masyarakat STIKes Hang Tuah Pekanbaru

\begin{abstract}
ABSTRAK
Target nasional pemberian ASI eksklusif adalah $80 \%$. Laporan Dinas Kesehatan Propinsi Riau, cakupan pemberian ASI Eksklusif untuk wilayah Riau tahun 2010 adalah 25,40\%. Puskesmas Rambah Hilir I merupakan salah satu dari 4 puskesmas di Kabupaten Rokan Hulu dengan angka pencapaian yang rendah yaitu 26,\% \%. Penelitian ini bertujuan untuk mengetahui hubungan pengetahuan ibu, pekerjaan ibu, informasi dari tenaga kesehatan dan dukungan keluarga dengan dengan pemberian ASI Eksklusif. Penelitian ini merupakan jenis penelitian analitik kuantitatif dengan jenis desain cross sectional, penelitian dilakukan selama 2 bulan di Wilayah Kerja Puskesmas Rambah Hilir I Kabupaten Rokan Hulu, dengan jumlah sampel sebanyak 81 orang. Alat ukur yang digunakan adalah kuesioner. Analisis data bivariat dengan uji Chi_Square. Hasil penelitian menunjukkan pengetahuan ibu, informasi tenaga kesehatan, dan dukungan keluarga berhubungan dengan pemberian ASI Eksklusif dengan p value masing-masing adalah 0,001, 0,006 dan 0,029. informasi dari tenaga kesehatan berhubungan dengan pemberian ASI Eksklusif dengan p value 0,006 dan dukungan keluarga berhubungan dengan pemberian ASI Eksklusif dengan $\mathrm{p}$ value adalah 0,029. Pekerjaan ibu tidak berhubungan dengan pemberian ASI Eksklusif dengan p value 0,590. Diharapkan bagi Puskesmas agar memberikan informasi tentang ASI Eksklusif mengacu pada sepuluh langkah menuju keberhasilan menyusui sehingga dapat meningkatkan pengetahuan ibu dan keluarga.
\end{abstract}

Kata Kunci : ASI Eksklusif, pengetahuan ibu, informasi dari tenaga kesehatan, dukungan keluarga.

\section{ABSTRACK}

National target for practice exclusive breastfeeding is $80 \%$. Riau Provincial health Department in 2010 reported that the scope of exclusive breastfeeding at 25.40\%. Report Rokan Hulu District Health Office, Rambah Hilir I public health center was one of four health centers that target attainment is still low at 26.5\%. This study aims to determine the relationship of maternal knowledge, maternal employment, information from health and family support to exclusivfeeding. The results obtained frequency of exclusive breastfeeding in the Rambah Hilir I public health center 35.8\%, $p$ value of knowledge capital variable maternal work, information from health and family support are 0.001, 0.590, 0.006 and 0.029. In conclusion, the frequency of exclusive breastfeeding in the Work Area Rambah Hilir I public health center at 35.8\% in 2012, the variables associated with exclusive breastfeeding is the variable of maternal knowledge, information from health and family support, and variables that are not related to the variable job mother.

Keywords: Exclusive breastfeeding, factors associated

\section{PENDAHULUAN}

Pemberian ASI secara Eksklusif dapat mencegah kematian balita sebanyak 13\%. Pemberian makanan pendamping ASI pada saat dan jumlah yang tepat dapat mencegah kematian balita sebanyak $6 \%$ sehingga pemberian ASI secara eksklusif selama 6 bulan dan dilanjutkan sampai usia $>2$ tahun bersama makanan pendamping ASI yang tepat dapat mencegah kematian balita sebanyak 19\% (Roesli, 2008).

Dalam Undang-Undang Republik Indonesia nomor 36 tentang kesehatan, khususnya pada Bab VII tentang gizi, pada pasal 142 ayat 1 , menyatakan : upaya perbaikan gizi dilakukan pada seluruh siklus kehidupan sejak dalam kandungan sampai dengan lanjut usia dengan prioritas kepada kelompok rawan, meliputi bayi dan balita, remaja perempuan, ibu hamil, dan ibu menyusui. Bayi, salah satu yang termasuk kedalam usia kelompok rawan gizi. Oleh sebab itu, sudah menjadi kewajiban bersama untuk memperhatikan keadaan gizi penerus bangsa pada usia bayi, balita dan seterusnya. Masih dalam UndangUndang yang sama, di dalam pasal 128 ayat 1 menyatakan setiap bayi berhak mendapatkan Air Susu Ibu (ASI) Eksklusif sejak dilahirkan selama 6 bulan, kecuali atas indikasi medis (UU RI No 36 tentang kesehatan tahun 2009). 
Keputusan Menteri Kesehatan Republik Indonesia No. 450/Men.Kes/SK/IV/2004 menyatakan bahwa bahwa Air Susu Ibu (ASI) adalah makanan terbaik bagi bayi karena mengandung zat gizi paling sesuai untuk pertumbuhan dan perkembangan bayi. Selanjutnya untuk mencapai pertumbuhan dan perkembangan bayi yang optimal ASI perlu diberikan secara Eksklusif sampai umur 6 (enam) bulan dan dapat dilanjutkan sampai anak berumur 2 (dua) tahun.

Hasil Riset Kesehatan Dasar (RISKESDAS) tahun 2007 menunjukan bahwa pemberian ASI Eksklusif selama enam bulan hanya mencapai 31\%. Hal ini masih jauh dari target pencapain pemberian ASI Eksklusif sebesar 80\% (Riskesdas, 2010)

Laporan Dinas Kesehatan Propinsi Riau, cakupan pemberian ASI Eksklusif untuk wilayah Riau tahun 2008 adalah $36,50 \%$, tahun 2009 sebesar $45,50 \%$ dan tahun 2010 adalah $25,40 \%$, Terjadi penurunan pada tahun 2010 (Dinkes Provinsi Riau 2010).

Di Kabupaten Rokan Hulu, pada tahun 2008 dari jumlah bayi 9.884 hanya $1.809(18.30 \%)$ bayi yang mendapat ASI Eksklusif. Pada tahun 2009, dari jumlah bayi 4.867 hanya $725(14,90 \%)$ bayi yang mendapat ASI Eksklusif. Tahun 2010 pemberian ASI Eksklusif sebesar 47,4\%. Dari data tersebut dapat dilihat terjadi penurunan dari tahun 2008 ke tahun 2009, namun cakupan ASI Eksklusif masih di bawah target nasional yaitu $80 \%$.

Di wilayah kerja Puskesmas Rambah Hilir I cakupan ASI Eksklusif pada tahun 2008 dari jumlah bayi 231 hanya 2 orang $(0,9 \%)$ bayi yang diberi ASI Eksklusif. Pada tahun 2009 dari jumlah bayi 222 hanya $12(5,4 \%)$ bayi yang diberi ASI Eksklusif. Pada tahun 2010 dari dari jumlah bayi 240 hanya 64 (26,5\%) Bayi yang diberi ASI eksklusif Hal ini menggambarkan masih rendahnya pemberian ASI Eksklusif di Puskesmas Rambah Hilir I dibandingkan dengan target nasional (Dinkes Kab Rokan Hulu 2010).

Semua Puskesmas yang terdapat di Kabupaten Rokan Hulu belum mencapai target nasional cakupan ASI Eksklusif (80\%). Puskesmas tertinggi pencapaian target ASI Eksklusif tahun 2010 adalah Puskesmas Tambusai Utara yaitu 61,1\% ( Dinkes Kab Rokan Hulu, 2010).

Sudah banyak penelitian yang mengungkap tentang pentingnya pemberian ASI. Pemberian ASI Eksklusif dapat mencegah 13\% kematian balita. Anak yang mendapat ASI memiliki resiko lebih rendah menderita penyakit infeksi, diare maupun alergi (Puslitbang gizi dan makanan, 2010).

Berdasarkan penelitian yang dilakukan oleh Yulisma (2009) bahwa pengetahuan tentang ASI memiliki hubungan terhadap pemberian ASI Eksklusif. Pawenrusi (2009) mengatakan, pekerjaan ibu memiliki hubungan terhadap pemberian ASI Eksklusif. Leoska (2009) menyebutkan informasi dari tenaga kesehatan memiliki hubungan dengan pemberian ASI Eksklusif. Nuraini (2010) mengatakan dukungan keluarga memiliki hubungan terhadap pemberian ASI Eksklusif.

Berdasarkan survei pendahuluan yang sudah dilakukan di wilayah kerja Puskesmas Rambah Hilir I, dari $10 \mathrm{ibu}$ yang ditanyakan tentang pemberian ASI Eksklusif hanya 4 orang ibu (40\%) yang memberikan ASI Eksklusif, dan 6 orang ibu $(60 \%)$ tidak memberikan ASI Eksklusif. Mereka beralasan ASI belum keluar, sehingga memberikan susu formula dan makanan salah satu contohnya pisang. Penelitian tentang pemberian ASI Eksklusif belum pernah dilakukan di wilayah kerja Puskesmas Rambah Hilir I. Oleh sebab itu peneliti tertarik untuk melakukan penelitian tentang faktor-faktor yang berhubungan dengan pemberian ASI Eksklusif di wilayah kerja Puskesmas Rambah Hilir I.

Tujuan penelitian ini adalah untuk mengetahui faktor-faktor yang berhubungan dengan pemberian ASI Eksklusif di wilayah kerja Puskesmas Rambah Hilir I.

\section{METODE}

Penelitian ini analitik kuantitatif dengan jenis disain cross sectional. Penelitian ini dilakukan dari bulan Mei-Juni tahun 2012. Populasi penelitian ini adalah ibu-ibu yang mempunyai bayi umur 7-12 bulan di wilayah kerja Puskesmas Rambah Hilir I, dengan sampel 81 responden. Pengumpulan data dilakukan dengan menggunakan kuesioner dengan cara angket, analisis data menggunakan analisis univariat dan bivariat menggunakan uji chi-square.

\section{HASIL}

Berdasarkan kuesioner yang dikumpulkan dari 81 responden diperoleh data tentang umur, pendidikan dan jenis pekrjaan. Secara lengkap deskripsi distribusi responden dapat dilihat dalam tabel 1 .

Tabel 1

Hasil Analisis Univariat

\begin{tabular}{lcc}
\hline Variabel & Jumlah & Persen \\
\hline Pengetahuan & & \\
Kurang Baik & 43 & $53,1 \%$ \\
Baik & 38 & $46,9 \%$ \\
Jumlah & 81 & $100 \%$ \\
Pekerjaan & & \\
Tidak Bekerja & 60 & $74,1 \%$ \\
Bekerja & 21 & $25,9 \%$ \\
Jumlah & 81 & $100 \%$ \\
Informasi dari Tenaga Kesehatan & & \\
Kurang & 51 & $63 \%$ \\
Baik & 30 & $37 \%$ \\
Jumlah & 81 & $100 \%$ \\
\hline
\end{tabular}

Page 68 


\section{Lanjutan Tabel 1}

\begin{tabular}{lll} 
Dukungan Keluarga & & \\
Tidak mendukung & 53 & $65,4 \%$ \\
Mendukung & 28 & $34,6 \%$ \\
Jumlah & 81 & $100 \%$ \\
Pemberian ASI & & \\
Tidak Eksklusif & 52 & $64,2 \%$ \\
Eksklusif & 29 & $35,8 \%$ \\
Jumlah & 81 & $100 \%$ \\
\hline
\end{tabular}

Hasil uji univariat bahwa sebagian besar responden memiliki pengetahuan kurang tentang ASI Ekslusif, banyak $(74,1 \%)$ responden yang tidak bekerja, 51 responden $(63,0 \%)$ yang kurang mendapat informasi dari tenaga kesehatan tentang ASI Eksklusif, sebagian besar responden tidak mendapat dukungan dari keluarga dalam memberikan ASI Eksklusif dan sebagian besar responden di wilayah penelitian tidak memberikan ASI Ekslusif kepada bayinya.

Tabel 2

Analisis Bivariat

\begin{tabular}{|c|c|c|c|c|c|c|c|c|}
\hline \multirow{3}{*}{ Variabel } & \multicolumn{4}{|c|}{ Pemberian ASI } & \multirow{2}{*}{\multicolumn{2}{|c|}{ Total }} & \multirow{3}{*}{ P Value } & \multirow{3}{*}{ OR (CI 95\%) } \\
\hline & \multicolumn{2}{|c|}{ Eksklusif } & \multicolumn{2}{|c|}{ Eksklusif } & & & & \\
\hline & $\mathbf{n}$ & $\%$ & $\mathbf{n}$ & $\%$ & $\mathbf{n}$ & $\%$ & & \\
\hline \multicolumn{9}{|l|}{ Pengetahuan } \\
\hline Kurang & 35 & 81,4 & 8 & 18,6 & 43 & 100 & 0,001 & 5,404 \\
\hline Baik & 17 & 44,7 & 21 & 55,5 & 38 & 100 & & $(1,989-14,686)$ \\
\hline \multicolumn{9}{|l|}{ Pekerjaan } \\
\hline Tidak Bekerja & 37 & 61,7 & 23 & 38,3 & 60 & 100 & 0,590 & 1,554 \\
\hline Bekerja & 15 & 71,4 & 6 & 28,6 & 21 & 100 & & $(0,528-4,578)$ \\
\hline \multicolumn{9}{|c|}{ Informasi dari nakes } \\
\hline Kurang & 39 & 76,5 & 12 & 23,5 & 51 & 100 & 0,006 & 4,250 \\
\hline Baik & 13 & 43,3 & 17 & 56,7 & 30 & 100 & & $(1,612-11,207)$ \\
\hline \multicolumn{9}{|c|}{ Dukungan Keluarga } \\
\hline Tidak ada & 39 & 73,6 & 14 & 26,4 & 53 & 100 & 0,029 & 3,214 \\
\hline Ada & 13 & 46,4 & 15 & 53,6 & 28 & 100 & & $(1,229-8,407)$ \\
\hline
\end{tabular}

Hasil uji bivariat bahwa variabel pengetahuan ibu berhubungan dengan pemberian ASI Eksklusif (pvalue $=0,001)$, dengan OR $=5,404$ (95\% CI 1,98914,682 ) artinya ibu yang memiliki pengetahuan kurang lebih resiko 5,4 kali tidak memeberikan ASI Eksklusif dibandingkan ibu yang berpengetahuan baik. Tidak ada hubungan antara variable pekerjaan ibu dengan pemberian ASI Eksklusif (pvalue $=0,590$ ) dengan OR $=1,554(95 \%$ CI $0,528-4,578)$.

Ada hubungan antara informasi dari nakes dengan pemberian ASI Eksklusif (pvalue = 0,006) dengan $\mathrm{OR}=4,250$ (95\% CI 1,612-11,207). Ibu yang kurang mendapatkan informasi dari tenaga kesehatan lebih berisiko 4,2 kali tidak memberikan ASI Eksklusif dibandingkan dengan ibu yang mendapatkan informasi dari tenaga kesehatan.

Ada hubungan dukungan keluarga dengan pemberian ASI Eksklusif (pvalue $=0,029$ ) dengan OR $=3,214(95 \%$ CI $1,229-8,407)$, ibu yang tidak mendapat dukungan keluarga mempunyai peluang 3,2 kali tidak memberikan ASI Eksklusif dibandingkan dengan ibu yang mendapat dukungan keluarga.

\section{PEMBAHASAN}

\section{Pengetahuan}

Dari hasil uji bivariat penelitian bahwa pemberian ASI Eksklusif lebih banyak pada ibu yang mempunyai pengetahuan baik $(55,3 \%)$ dibandingkan ibu yang mempunyai pengetahuan kurang $(18,6 \%)$. Hasil uji statistik diperoleh $\mathrm{p}$ value 0,001 berarti $\mathrm{p}<$ 0,05 , maka ada hubungan yang bermakna pengetahuan dengan pemberian ASI Eksklusif.

Dari hasil penelitian di atas dapat kita ambil kesimpulan bahwa faktor pengetahuan berhubungan dengan pemberian ASI eksklusif, semakin tinggi tingkat pengetahuan seorang ibu, maka semakin tinggi pula kesadarannya untuk memberikan ASI Eksklusif kepada bayinya.

Hasil penelitian ini sama dengan penelitian Yulisma (2009) di Puskesmas Sidomulyo Kecamatan Tampan Kota Pekanbaru diperoleh hasil yang bermakna antara pengetahuan dengan pemberian ASI Eksklusif, dimana semakin tinggi tingkat pengetahuan responden maka semakin tinggi pula tingkat pemberian 
ASI Eksklusif dan sama dengan penelitian Rohani (2009), Mailiza (2008), Nurul (2008), yang menyatakan ada hubungan yang bermakna pengetahuan dengan pemberian ASI Eksklusif.

Pengetahuan kesehatan akan berdampak kepada perilaku sebagai hasil jangka menengah (intermediate impact) dari pendidikan kesehatan. Pengetahuan atau kognitif merupakan domain yang sangat penting untuk terbentuknya tindakan seseorang. Selanjutnya prilaku kesehatan akan berpengaruh pada meningkatnya indikator kesehatan masyarakat sebagai keluaran (outcome) pendidikan kesehatan (Notoadmodjo, 2007).

Dari hasil penelitian yang dilakukan dapat disimpulkan bahwa pengetahuan ibu yang cukup dapat mendasari untuk tindakan pemberian ASI eksklusif kepada bayinya, dimana ibu dengan pengetahuan baik akan lebih memahami pentingnya pemberian dan manfaat ASI Eksklusif. Kemudian ibu tersebut akan mengaplikasikan dan merealisasikan secara langsung pemberian ASI Eksklusif kepada bayi mereka.

Dalam Sepuluh Langkah Menuju Keberhasilan Menyusui, petugas kesehatan mempunyai peranan untuk memberikan informasi kepada ibu hamil tentang manfaat menyusui dan pelaksanaannya, sehingga ibu hamil mempunyai pengetahuan tentang ASI Eksklusif. Untuk memberikan informasi petugasi perlu diberi pelatihan dalam hal pengetahuan dan keterampilan untuk menerapkan kebijakan peningkatan pemberian ASI.

\section{Pekerjaan}

Dari hasil uji bivariat penelitian bahwa pemberian ASI Eksklusif lebih banyak pada ibu yang tidak bekerja yaitu $38,3 \%$ dibandingkan dengan ibu yang bekerja yaitu $28,6 \%$. Hasil uji statistik diperoleh pvalue 0,590 berarti $\mathrm{p}>0,05$, maka tidak ada hubungan yang bermakna pekerjaan dengan pemberian ASI Eksklusif.Penelitian ini sejalan dengan penelitian Candriasih (2010), Asma (2009), Aswa (2009) yang menyatakan tidak ada hubungan pekerjaan dengan pemberian ASI Eksklusif.

Menurut Roesli (2008) bekerja bukan alasan untuk menghentikan pemberian ASI secara eksklusif selama paling sedikit 4 bulan dan bila mungkin sampai 6 bulan. Dengan pengetahuan yang benar tentang menyusui, adanya perlengkapan memerah ASI, dan dukungan lingkungan kerja, seseorang ibu yang bekerja dapat tetap memberikan ASI secara eksklusif. Dalam SKB 3 Menteri tentang hak ibu bekerja yang menyusui, tempat kerja yang mempuyai fasilitas menyusui, dan pemberian izin kepada ibu untuk menyusui bayinya akan bisa menerapkan kebijakan peningkatan pemberian ASI.

\section{Informasi dari Tenaga Kesehatan}

Dari hasil uji bivariat bahwa pemberian ASI Eksklusif lebih banyak pada ibu yang mendapat informasi baik dari tenaga kesehatan yaitu $56,7 \%$ dan ibu yang kurang mendapat informasi dari tenaga kesehatan dan memberikan ASI Eksklusif yaitu 23,5\%. Hasil uji statistik $p$ value 0,006 berarti $p$ value $<0,05$, kesimpulannya ada hubungan yang bermakna informasi dari tenaga kesehatan dengan pemberian ASI Eksklusif

Hasil penelitian ini sama dengan penelitian Leoska (2009) dimana hasil uji statistiknya $p$ value 0,022 berarti nilai $\mathrm{p}$ value $<0,05$ sehingga terdapat hubungan informasi dari tenaga kesehatan dengan pemberian ASI Eksklusif. Sebenarnya menyusui, khususnya yang secara eksklusif merupakan cara pemberian makan alamiah. Namun sering kali ibu ibu kurang mendapatkan informasi bahkan sering kali mendapat informasi yang salah tentang manfaat ASI ekskusif, tentang bagaimana cara menyusui yang benar, dan apa yang harus dilakukan bila timbul kesukaran dalam menyusui bayinya (Roesli, 2000).

Berdasarkan Keputusan Menteri Kesehatan RI No 450/MENKES/SK/IV/2004 tentang pemberian ASI secara eksklusif butir b menyatakan semua tenaga kesehatan yang bekerja di sarana pelayanan kesehatan agar menginformasikan kepada semua ibu yang baru melahirkan untuk memberikan ASI Eksklusif. Informasi dari tenaga kesehatan tentang ASI Eksklusif bisa menambah pengetahuan ibu, sehingga ibu mempunyai motivasi untuk memberikan ASI Eksklusif.

\section{Dukungan Keluarga}

Dari hasil penelitian diketahui bahwa ibu yang mendapat dukungan keluarga sebagian besar memberikan ASI Eksklusif kepada bayinya. P value yang diperoleh adalah 0,000 nilai ini menunjukkan bahwa $\mathrm{P}$ value $0,000<0,05$. Jadi dapat disimpulkan bahwa ada hubungan dukungan keluarga dengan pemberian ASI Eksklusif. Nilai OR 6,786 (CI = 2,43218,932) menunjukkan bahwa responden yang tidak mendapat dukungan keluarga berisiko untuk tidak memberikan ASI Eksklusif sebesar 6,786 kali dibandingkan dengan responden mendapat dukungan keluarga.

Pada penelitian Nuraini (2010), Lean (2011) menyatakan bahwa dukungan keluarga memiliki hubungan dengan pemberian ASI Eksklusif. Dalam pemberian ASI Eksklusif dukungan keluarga sangat penting, terutama suami. Dikarenakan menyusui kadang tidak mudah dan sangat melelahkan. Dari semua dukungan bagi ibu menyusui, dukungan suami adalah dukungan paling berarti bagi ibu. Suami dapat berperan aktif dalam keberhasilan pemberian ASI dengan jalan memberikan dukungan secara emosional dan bantuan praktis lainnya (Roesli,2000)

Berdasarkan Undang-Undang No 36 tahun 2009 tentang kesehatan BabVII tentang gizi, pasal 28 butir b menyatakan pihak keluarga, pemerintah daerah 
dan masyarakat harus mendukung ibu bayi secara penuh dengan penyedian waktu dan fasilatas khusus. Faktor dukungan keluarga berhubungan dengan pemberian ASI eksklusif. Semakin besar dukungan keluarga baik suami, orang tua dan mertua, maka semakin besar motivasi ibu untuk memberikan ASI Eksklusif.

\section{KESIMPULAN}

Pemberian ASI Eksklusif di wilayah kerja Puskesmas Rambah Hilir I masih rendah sebesar $35,8 \%$. Ada 3 variabel independen yang berhubungan dengan pemberian ASI Eksklusif adalah pengetahuan ibu, informasi dari tenaga kesehatan dan dukungan keluarga sedangkan variabel yang tidak berhubungan dengan pemberian ASI Eksklusif yaitu pekerjaan ibu.

\section{SARAN}

Diharapkan bagi Puskesmas agar dapat memberikan informasi tentang ASI Eksklusif mengacu pada sepuluh Langkah Menuju Keberhasilan Menyusui dan meningkatkan kerjasama program gizi, program KIA/KB dan program Promkes dalam memberikan penyuluhan kepada ibu-ibu tentang ASI Eksklusif.

\section{DAFTAR PUSTAKA}

Ambarwati. (2008). Asuhan Kebidanan Nifas. Yogyakarta: Mitra Cendikia.

Depkes RI. ( 2005). Ibu Bekerja Tetap Memberikan Air Susu Ibu (ASI). Jakarta.

Depkes RI. (2007). Pelatihan Kader Kesehatan dan Tokoh Masyarakat dalam Pengembangan Desa Siaga. Jakarta

Depkes RI. (2009). Pemberian Air Susu Ibu dan Makanan Pendamping ASI: Jakarta

Handayani, A. (2012). Mengapa Seorang Ibu Harus Menyusui. Yogjakarta: FlashBooks

Kristiyanasari, W. (2009). ASI, Menyusui \& Sadari. Yogyakarta: Nuha Medika.

Kementrian Pemberdayaan Perempuan. (2010). Pedoman Peningkatan Penerapan 10 Langkah Menuju Keberhasilan Menyusui yang Responsif Gender bagi Pusat dan Daerah. Kementrian
Pemberdayaan Perempuan dan Perlindungan Anak Republik Indonesia.

Nugroho, T. (2011). ASI dan Tumor Payudara. Yogyakarta: Nuha Medika

Notoatmomodjo, S. (2005). Metode Penelitian Kesehatan. Jakarta: Rineka Cipta.

Notoatmomodjo, S.(2007). Kesehatan Masyarakat Ilmu dan Seni. Jakarta : Rineka Cipta.

Pawenrusi. (2011). Faktor yang Berhubungan dengan Pemberian ASI eksklusif di Kelurahan Tamamaung Kota Makasar. Jurnal Media Gizi Pangan Vol XI Edisi 6.

PP-ASI, (2009). Strategi Nasional (online) (www.Gizi.net/kebijakan Gizi/download/ doc diakses 01 April 2011).

Puskesmas Rambah Hilir I. (2011). Profil Puskesmas Rambah Hilir I.

Puslitbang Gizi dan Makanan. (2010). Ibu Yakin ASI Pasti Lancar. Jakarta: Kementrian Kesehatan Republik Indonesia

Rizki, A. (2009). Hubungan Pengetahuan, Sikap Ibu dan Dukungan Keluarga terhadap Pemberian ASI eksklusif pada Bayi Usia 6 -12 Bulan. FKM Universitas Airlangga.

Roesli, U. (2000). Mengenal ASI Eksklusif. Jakarta: Trubus Agriwidya

Roesli, U. (2008). Manfaat ASI dan Menyusui. Jakarta: FKU

Rohani. (2007). Pengaruh Karakteristik Ibu Menyusui Terhadap Pemberian ASI Eksklusif di Wilayah Kerja Puskesmas Teluk Kecamatan Secanggang Kabupaten Langkat. USU Repository

Sriningsih, I. (2010). Faktor Demografi, Pengetahuan Ibu tentang Air Susu Ibu dan Pemberian ASI Eksklusif. Jurnal Kesehatan Msyarakat 6(2) 100-106

Undang - Undang RI No 36 Tahun 2009 tentang Kesehatan. (2009). Jakarta

Walker, A. (2006). Makan yang Sehat untuk Bayi dan Anak-Anak. Jakarta: Bhuana Ilmu Populer 